AperTO - Archivio Istituzionale Open Access dell'Università di Torino

Electrodeposited platinum on de-alloyed nanoporous gold with enhanced electro-catalytic performance

This is a pre print version of the following article:

Original Citation:

Availability:

This version is available http://hdl.handle.net/2318/1691355

since 2019-03-13T15:28:14Z

Published version:

DOI:10.1016/j.apsusc.2019.01.099

Terms of use:

Open Access

Anyone can freely access the full text of works made available as "Open Access". Works made available under a Creative Commons license can be used according to the terms and conditions of said license. Use of all other works requires consent of the right holder (author or publisher) if not exempted from copyright protection by the applicable law. 


\title{
Electrodeposited platinum on de-alloyed nanoporous gold with enhanced electro-catalytic performance
}

\author{
Yanpeng Xue ${ }^{1,2 *}$, Federico Scaglione ${ }^{2 *}$, Paola Rizzi ${ }^{2}$, Livio Battezzati ${ }^{2}$ \\ Pierre Denis ${ }^{3}$, Hans-Jörg Fecht ${ }^{3}$ \\ ${ }^{1}$ National Center for Materials Service Safety, University of Science and Technology Beijing, \\ Xueyuan Road 30, 100083, Beijing, China \\ ${ }^{2}$ Dipartimento di Chimica e Centro Interdipartimentale NIS (Nanostructured Surfaces and \\ Interfaces), Università di Torino, Via Pietro Giuria 7, 10125 Torino, Italy \\ ${ }^{3}$ Institute of Micro and Nanomaterials, University of Ulm, Albert-Einstein-Allee 47, \\ 89081 Ulm, German
}

*Corresponding Author: xueyanpeng789@163.com; federico.scaglione@unito.it

\begin{abstract}
In this work, Pt nanoparticles were electrodeposited through cyclic voltammetry technique on three dimensional nanoporous gold, which was prepared by chemical de-alloying of Au-based metallic glass precursor in the form of ribbon. The electro-catalytic properties of the as-prepared samples were tested through potential cycling towards methanol oxidation in alkaline solution. Current density plots vs scan numbers indicate that the electrodes are active for the electro-oxidation of methanol and the Pt electrodeposited on gold ligaments contributes in increasing catalytic properties. In particular, results indicate that nanoporous gold with 30 cycles $\mathrm{Pt}$ electrodeposition exhibits competitive higher activity and longer durability towards methanol electro-oxidation.
\end{abstract}

\section{Introduction}

Nanoporous metals have gained interest in the recent years thanks to their easy route of fabrication and versatile properties. Fabrication implies usually a de-alloying process: a less noble constituent of an precursor alloy is dissolved, while the noble metal atoms diffuse at the metal-electrolyte interfaces to form 3D interconnected open-pore structure[1,2]. De-alloying can be chemical when performed in suitable electrolytes of acids or bases depending on the starting alloy, or electro-chemical when the chemical de-alloying is assisted by an external potential supply. This process has been dealt with in a number of papers, most of them involving solid solution of binary systems[3], metastable eutectics[4]or metallic glasses precursors[5,6] leading to nanoporous metals of different elements including gold[7,8], copper[9,10], silver[11] and iron[12]. When de-alloyed from metallic glasses precursors, the nanoporous metal possess many active sites which involved the nucleation and growth compared with crystalline alloy counterparts[13]. Recently the advantage of de-alloying an amorphous 
precursor instead of a crystalline one has been underlined, demonstrating that the germination of crystals from the amorphous matrix and their impingements create a knobby and irregular ligaments with defects and retained atoms aiming to improve catalytic and activities properties[14]. Furthermore nanoporous metals can be tailored in size by tuning properly etching condition such as temperature, concentration and type of the electrolyte and time of treatment.

In order to decrease the greenhouse gas emissions, direct methanol fuel cells (DMFCs) have recently received much attention[15,16]. Because of its high energy densities and low operation temperatures, DMFCs will be one of the promising alternative sources to replace conventional fossil power[17,18]. However, the carbon-supported Pt electro-catalyst exhibits high electro-catalytic properties towards the methanol oxidation, but easy to lose its efficiency due to the poisons of $\mathrm{CO}$ species[19,20]. On the other hand, the Au electro-catalysts displayed long durability in fuel cells because of the inhibition of the $\mathrm{CO}$ species poisons[21]. Nanoporous $\mathrm{Au}$ fabricated through the de-alloying methods exhibits high promising applications in electro-catalysis due to their particular interconnected bicontinuous nanoporous structure with large surface area and fast ionic transport[22-24]. Due to the improvement of catalyst activity and selectivity of bimetallic nanostructured materials[24], Ding's group fabricated bimetallic Pt-nanoporous Au catalysts by immersion-electrodeposition technique to load uniformly $\mathrm{Pt}$ on nanoporous $\mathrm{Au}$ de-alloyed from AuAg alloy, which exhibited much better performance than commercial $\mathrm{Pt} / \mathrm{C}$ towards methanol electro-oxidation under the similar platinum utilization values[25,26]. Xiao et al obtained hybrid Pt-Au catalysts by electroless deposition $\mathrm{Pt}$ on nanoporous $\mathrm{Au}$ fabricated by de-alloying $\mathrm{Au}_{50} \mathrm{Ag}_{50}$ alloy, which greatly enhance the efficiency of Pt usage and improve the intermediate species tolerance compared with pure Pt electrode. However, here bare nanoporous gold (NPG) does not have any reactivity for methanol oxidation, acting solely as a scaffold for the deposited Pt, that is the real catalyst [27].

In this work, we introduced a novelty and a huge improvement in the catalytic activity of electrodes for methanol oxidation: the novelty resides in our NPG, prepared by chemical de-alloying of a metallic glass precursor that is itself a good catalyst for the reaction [30 cross ref. Maria's paper]. Activity of NPG is originated by the defective and nano-grained structure of ligaments, peculiar when de-alloying an amorphous precursor. The improvement is reached with Pt nanoparticles deposited by cyclic voltammetry technique on NPG surface. Their contribution in increasing further the electro-catalytic properties towards methanol oxidation results from synergic effects between the nanoporous Au core and Pt shell structure.

\section{Experimental:}

An $\mathrm{Au}_{20} \mathrm{Cu}_{48} \mathrm{Ag}_{7} \mathrm{Pd}_{5} \mathrm{Si}_{20}$ master alloy was prepared by arc melting the pure elements (Au: 99.99\%, Ag, Cu, Pd: 99.99\%, Si: 99.9995\%) in Ti-gettered Argon atmosphere. 
The ingot was melted by induction in a quartz crucible of a melt-spinning apparatus and rapidly solidified onto a rotating copper wheel at a linear speed of $25 \mathrm{~m} / \mathrm{s}$. The thickness of the resulting amorphous ribbon is around $20 \mu \mathrm{m}$ and the width is around $2 \mathrm{~mm}$. Samples of $15 \mathrm{~mm}$ in length were cut from the ribbon.

Chemical de-alloying of the as-spun ribbons was conducted in mixture of $10 \mathrm{M}$ $\mathrm{HNO}_{3}$ and $0.5 \mathrm{M} \mathrm{HF}$ at $70{ }^{\circ} \mathrm{C}$ for 4 hours, conditions optimized in previous works $[28,29]$. After chemical de-alloying, the de-alloyed samples were deeply rinsed with distilled water. On nanoporous gold, Pt nanoparticles were electrodeposited using cyclic voltammetry (CV) technique in an electrolyte solution of $0.7 \mathrm{mM} \mathrm{H}_{2} \mathrm{PtCl}_{6}$ and $0.5 \mathrm{M} \mathrm{H}_{2} \mathrm{SO}_{4}$ from -0.2 to $0.5 \mathrm{~V}$ vs. $\mathrm{Ag} / \mathrm{AgCl}$ with a scan rate of $20 \mathrm{mV} / \mathrm{s}$ for 5 and 30 cycles respectively.

The surface morphology of de-alloyed samples was investigated by scanning electron microscopy (SEM) before and after de-alloying and electrodeposition and their compositions were checked by energy dispersive X-ray spectroscopy (EDS). The average size of ligament was measured at their narrower necks using a Leica software[6]. The structure of the materials was studied by X-ray diffraction (XRD) using $\mathrm{Cu}$ Ka wavelength in Bragg-Brentano mode.

Electrochemical measurements were performed with an Autolab workstation. A conventional three-electrode configuration set up was used, an $\mathrm{Ag} / \mathrm{AgCl}$ (saturated $\mathrm{KCl}$ solution) electrode as the reference electrode, platinum foil as the counter electrode and the as-prepared samples as working electrode respectively. Before testing, the as-prepared samples were activated for 1 hour in concentrated $\mathrm{HNO}_{3}$ and rinsed in de-ionized water for 15 minutes. The working electrode was scanned for up to 10 cycles until the electrode was stabilized at a scan rate of $20 \mathrm{mV} / \mathrm{s}$ in $0.5 \mathrm{M} \mathrm{KOH}$ solution. The active electrochemical surface area was calculated according to the literature[27] and the current densities were normalized by making use of the electrochemical active surface area of each electrode. The electro-catalytic activity and the durability of the as-prepared samples were tested by performing 100 and 300 cycles at room temperature in $0.5 \mathrm{M} \mathrm{KOH}$ and $5 \mathrm{M} \mathrm{CH}_{3} \mathrm{OH}$ solution. Electrolytes were freshly prepared from chemical grade reagents and Milli-Q deionised water (18.2 M 2 ).

\section{Results and discussion}

Self-standing nanoporous gold (NPG) suitable as electro-catalytic electrodes was fabricated by chemical de-alloying in a mixture of $10 \mathrm{M} \mathrm{HNO}_{3}$ and $0.5 \mathrm{M} \mathrm{HF}$ at $70^{\circ} \mathrm{C}$ for 4 hours from the $\mathrm{Au}_{20} \mathrm{Cu}_{48} \mathrm{Ag}_{7} \mathrm{Pd}_{5} \mathrm{Si}_{20}$ metallic glass precursor, which was selected because it was monolithic phase with homogeneous composition and structure and the resultant ligaments were composed of multiple crystals [13]. After chemical de-alloying, the SEM image of NPG shown in Fig.1a reveals a uniform nanostructure composed of nanopores and ligaments with average size of around $60 \mathrm{~nm}$. Ligaments present the typical features resulting from de-alloying of an amorphous precursor .i.e. a rough and knobby surface constituted by several grains of nanometer size impinged together (see inset Fig.1a); such a morphology, in particular, has been proved having high electro-catalytic activity, compared with ligaments of similar size but fabricated 
from a crystalline precursor, thanks to retained atoms of $\mathrm{Ag}$ and $\mathrm{Pd}$ and under-coordinated sites due to surface kinks and originated by grain boundaries of impinged crystals during de-alloying process[30,31].

XRD pattern demonstrates the formation of face-centered cubic (fcc) Au from the amorphous state after chemical de-alloying at $70^{\circ} \mathrm{C}$ for 4 hours (Fig.S1). Lattice parameter measured by a Rietveld refinement is close to that of pure $\mathrm{Au}$ within the experimental error. EDS performed on the NPG surface samples shows traces of Pd and $\mathrm{Ag}$ [29], not affecting the lattice parameter. On de-alloyed nanoporous gold, Pt electrodeposition was achieved by cyclic voltammetry technique in an electrolyte solution of $0.7 \mathrm{mM} \mathrm{H}_{2} \mathrm{PtCl}_{6}$ and $0.5 \mathrm{M} \mathrm{H}_{2} \mathrm{SO}_{4}$ from -0.2 to $0.5 \mathrm{~V}$ vs. $\mathrm{Ag} / \mathrm{AgCl}$ for 5 and 30 cycles (Fig.S2). The reduction peak around $-0.1 \mathrm{~V}$ can be assigned to the Pt reduction at the NPG/electrolyte interface. After 5 cycles Pt electrodeposition, the oxidation peak of $\mathrm{Au}$ around $+0.25 \mathrm{~V}$ decreases, demonstrating the tiny Pt nanoparticles formed on the ligament surface (Fig.1b). Since the Pt electrodeposition is a crystal nucleation and growth process, the platinum ions are electro-reduced under the applied electric field to atoms, then absorbed and assembled on the gold ligament surface; in first stages, deposition starts occurring preferentially on steps or kink sites over other sites[26,32], then it spreads on the surface. With the increase of cycling, the oxidation peak of $\mathrm{Au}$ continues to decrease. After 30 cycles (Fig.1c), small Pt nanoparticles cover the top surface of Au ligaments without reaching a full coverage; at this stage, Pt nanoparticles are not coalesced. From the EDS measurement, the Pt content after 30 cycles electrodeposition can reach 4.77 at. $\%$. 

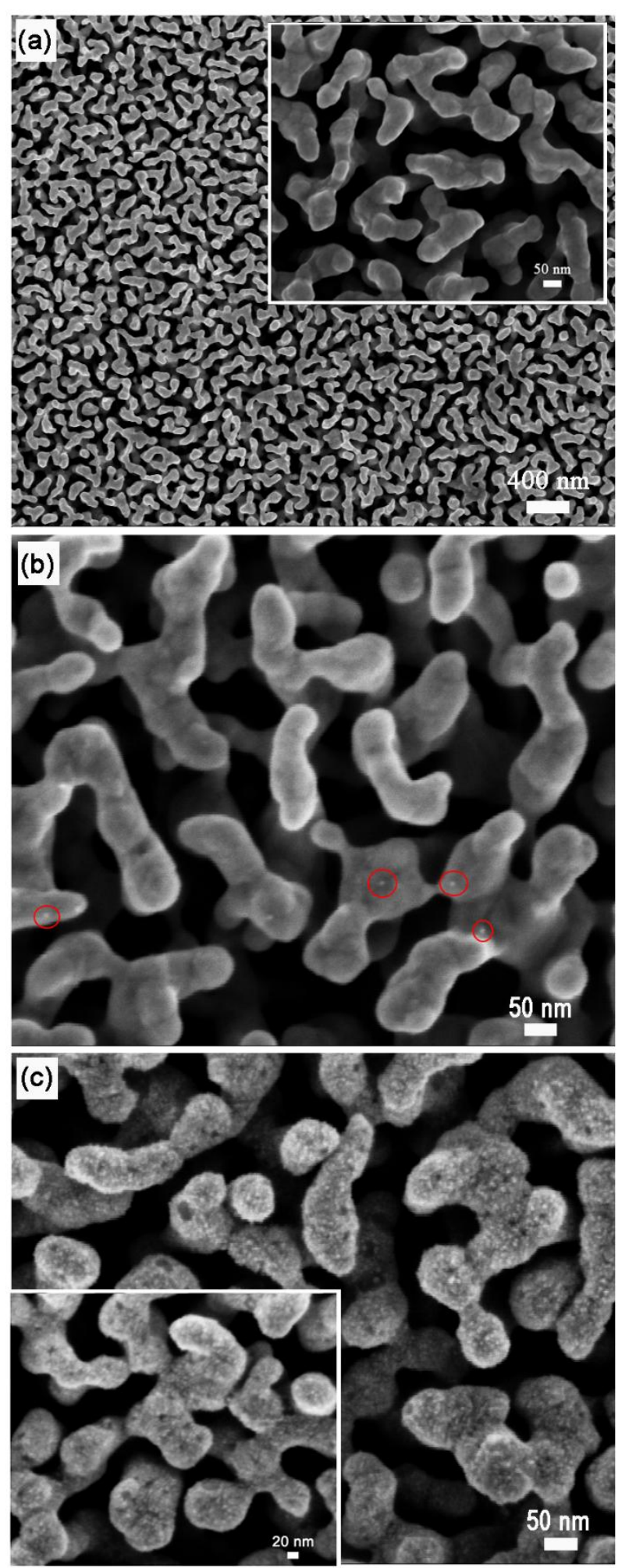

Figure 1. SEM images of (a) the $\mathrm{Au}_{20} \mathrm{Cu}_{48} \mathrm{Ag}_{7} \mathrm{Pd}_{5} \mathrm{Si}_{20}$ (at.\%) ribbon after chemical de-alloying in $10 \mathrm{M}$ $\mathrm{HNO}_{3}+0.5 \mathrm{M} \mathrm{HF}$ at $70{ }^{\circ} \mathrm{C}$ for 4 hours. Samples Pt deposited on nanoporous gold in $0.7 \mathrm{mM} \mathrm{H}_{2} \mathrm{PtCl}_{6}$ and $0.5 \mathrm{M} \mathrm{H}_{2} \mathrm{SO}_{4}$ with scan rate of $20 \mathrm{mV} / \mathrm{s}$ for (b) 5 cycles and (c) 30 cycles. Insets show the corresponding high magnification images.

After Pt electrodeposition, the electrochemical behaviors of the as-prepared samples were checked by cyclic voltammetry (CV) scans in $0.5 \mathrm{M} \mathrm{KOH}$ aqueous 
solution for 10 cycles (Fig.2a). The results suggest the occurrence of various processes due to their different amount of Pt loading. The formation of Au oxides around $+0.25 \mathrm{~V}$ is apparent for all samples[33], which also confirms the SEM results that the electrodeposited Pt nanoparticles are not fully covered the nanoporous gold ligaments surface after 30 cycles. Furthermore, the Au oxides reduction peak around $-0.12 \mathrm{~V}$ to $+0.18 \mathrm{~V}$ in the reverse scan shifts negatively and decreases after Pt electrodeposition. After 5 cycles of Pt electrodeposition, the hydrogen adsorption/desorption peaks from $\mathrm{Pt}$ are observed ranging from $-0.8 \mathrm{~V}$ to $-0.6 \mathrm{~V}$ and the reduction peak of $\mathrm{Pt}$ oxides around $-0.5 \mathrm{~V}$ to $-0.25 \mathrm{~V}$ appears, which confirms the occurrence of Pt electrodeposition. After 30 cycles of $\mathrm{Pt}$ electrodeposition, the hydrogen adsorption/desorption peak and reduction peak of $\mathrm{Pt}$ oxides increase. We also performed $\mathrm{CV}$ scans in $0.5 \mathrm{M} \mathrm{H}_{2} \mathrm{SO}_{4}$ aqueous solution which confirms this phenomena (Fig.S3).

To study the electro-catalytic properties, the as-prepared samples was measured towards methanol electro-oxidation under the same measurement conditions. On nanoporous gold, the onset potential towards methanol oxidation is around $-0.3 \mathrm{~V}$ and two well-defined oxidation peaks around $0.0 \mathrm{~V}$ and $0.3 \mathrm{~V}$ were observed towards methanol oxidation (Fig.2b), which is consistent with the methanol electro-oxidation catalyzed by nanoporous gold to formate ions in the potential range from $-0.1 \mathrm{~V}$ to 0.4 $\mathrm{V}[34,35]$. Bare NPG itself is active as catalyst for the reaction. A sharp increase in current density can be observed above $0.45 \mathrm{~V}$, consistent with the methanol electro-oxidation to carbonates above this potential. Compared with NPG electrode, the as-prepared Pt modified NPG electrodes exhibited a broad primary oxidation peak in the forward scan involving the electrochemical oxidation of methanol molecules to $\mathrm{CO}_{2}$ and the secondary oxidation peak during the reverse scan relating to further oxidation of the carbonaceous intermediates[26]. After 5 cycles Pt electrodeposition, the onset potential towards methanol oxidation on Pt modified NPG started at about $-0.7 \mathrm{~V}, 400 \mathrm{mV}$ more negative than that of NPG, which is similar to that of Pt-functionalized nanoporous gold bowls[36], indicating that the bi-metallic nanostructured Pt deposited on NPG can immediately facilitate the electro-oxidation reaction of methanol. The broader primary oxidation peak can be observed ranging from $-0.7 \mathrm{~V}$ to $0.4 \mathrm{~V}$ and the oxidation current density is about two times higher than that of NPG (Fig.2a). Compared with 5 cycles Pt electrodeposition, the area towards methanol electro-oxidation increases after 30 cycles Pt electrodeposition. This result could be attributed to the synergistic catalytic function of the Pt nanoparticles and uncovered NPG[36,37]. Firstly, the electro-catalytic abilities toward methanol oxidation of Pt nanoparticles and NPG are both very strong, the intermetallic interaction between Pt nanoparticles and NPG providing larger number of active sites for higher electro-catalytic activity. Secondly, the chemisorbed $\mathrm{OH}^{-}$anions on the uncovered gold ligament sites would assist the oxidation of CO-like intermediates[38] and the poisoned $\mathrm{Pt}$ was regenerated to take part in the oxidation of methanol. During the forward scan $\mathrm{OH}^{-}$anions are strongly chemisorbed on the porous surfaces forming oxidized species working as intermediate in the oxidation of methanol and promoting further oxidation of carbonaceous intermediates accumulated on $\mathrm{Pt}$ nanoparticles 
[25,27,39]. The density functional theory calculations suggested the gold atoms surrounding $\mathrm{Pt}$ atoms in the bi-metallic nanostructure can oxidize the CO-like intermediates or providing oxygenated species, which may partially release the $\mathrm{CO}$ poisoning effect[26]. Furthermore, previous literature has shown that the ratio of the forward anodic peak current $\left(\mathrm{I}_{\mathrm{f}}\right)$ to the reverse anodic peak current $\left(\mathrm{I}_{\mathrm{b}}\right), \mathrm{I}_{\mathrm{f}} / \mathrm{I}_{\mathrm{b}}$, could be used to evaluate the catalyst tolerance to carbonaceous species accumulation[26,27]. A high $\mathrm{I}_{\mathrm{f}} / \mathrm{I}_{\mathrm{b}}$ indicates good oxidation of methanol to carbon dioxide during the anodic scan and lower accumulation of carbonaceous resides on the catalytic surface. A low $\mathrm{I}_{\mathrm{f}} / \mathrm{I}_{\mathrm{b}}$ ratio shows the converse case. The ratios for NPG, Pt deposited for 5 cycles and Pt deposited for 30 cycles are 5.01, 1.54 and 1.1 respectively, larger than that of commercial Pt/C catalysts[40], which demonstrated that NPG de-alloyed from metallic glass precursor can suppress the formation of CO-like poisoning species. With the occurrence of Pt electrodeposition, more Pt nanoparticles cover the gold ligament surface, the ratio $\mathrm{I}_{\mathrm{f}} / \mathrm{I}_{\mathrm{b}}$ decreases and more carbonaceous intermediates are oxidized during the reverse scan.

A deeper comparison of $\mathrm{I}_{\mathrm{f}} / \mathrm{I}_{\mathrm{b}}$ ratio with literature data is however difficult due to the different experimental conditions. It is indeed reported [35 cross ref.], that the sweep rate, the type of electrolyte and methanol content affect the electro-oxidation of the molecules at the NPG electrode. In particular, since the first stages of reaction are mediated by a slow rate process of $\mathrm{OH}^{-}$chemisorption on NPG surface, a slow scan rate is favorable to the electro-oxidation reaction; nevertheless when the slower is the scan rate, the smaller is the peak corresponding to the gold oxide reduction in the negative-going potential sweep with consequence to the $I_{f} / I_{b}$. The ratio is then also affected by the content of methanol in the electrolyte being the amount of ethanol directly correlated with the oxidation current density. Finally the acidic or the basic environment for experiments is important being the pre-oxidation state of NPG surface more favored in a basic solution instead of an acidic one. Those remarks are extended to Pt deposited NPG samples, where Au active sites synergically improve tolerance to carbonaceous intermediates reducing poisoning of $\mathrm{Pt}$ sites during electro-oxidation reaction. 

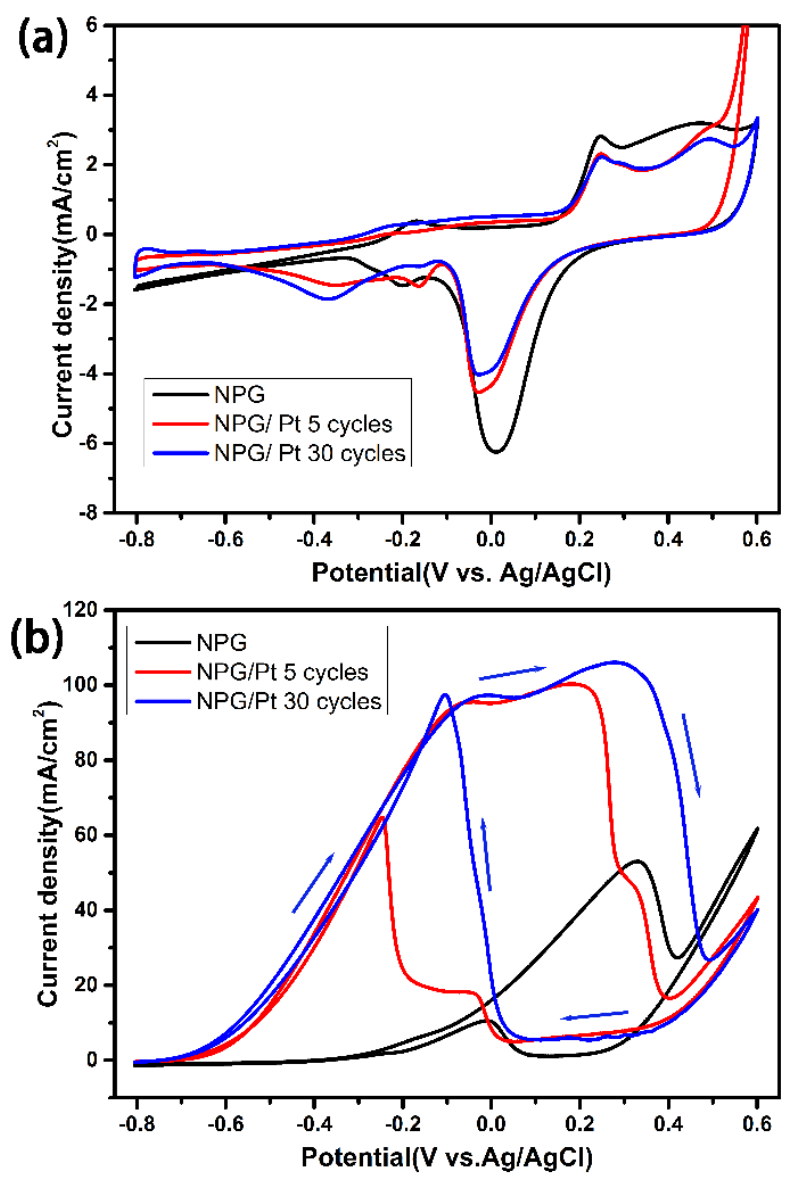

Figure 2. CV curves of as-prepared samples in (a) $0.5 \mathrm{M} \mathrm{KOH}$ and (b) $0.5 \mathrm{M} \mathrm{KOH}+5.0 \mathrm{M} \mathrm{CH}_{3} \mathrm{OH}$ with a scan rate of $20 \mathrm{mV} / \mathrm{s}$, normalized with geometrical surface area.

The electrochemical stability of the as-prepared samples was investigated by performing multiple $\mathrm{CV}$ cycles in $0.5 \mathrm{M} \mathrm{KOH}+5 \mathrm{M} \mathrm{CH}_{3} \mathrm{OH}$ solution. For NPG sample, the normalized current density decreased rapidly and reached values below 0.3 $\mathrm{mA} / \mathrm{cm}^{-2}$ after 100 cycles (Fig.3a) because of the progressive coverage of Au active sites by oxidized species of less noble elements, especially $\mathrm{Cu}$, a trace due to de-alloying coming from the inner ligaments and diffused in the top layer during the upward scan[30]. For sample of NPG with 5 cycles Pt electrodeposition (Fig.3b), with the potential cycling the area of methanol electro-oxidation reaction decreases and the ratio $\mathrm{I}_{\mathrm{f}} / \mathrm{I}_{\mathrm{b}}$ increases quickly, which indicates that the nanostructured bimetallic Pt-NPG catalyst loses their electro-catalytic activity towards methanol electro-oxidation and more gold ligament surfaces expose to the electrolyte. After $100 \mathrm{CV}$ cycles the normalized current density is still $0.75 \mathrm{~mA} / \mathrm{cm}^{-2}$. For sample of NPG with 30 cycles Pt electrodeposition (Fig.3c), the normalized current density reaches $0.81 \mathrm{~mA} / \mathrm{cm}^{-2}$ after $100 \mathrm{CV}$ cycles. With the potential cycling the area of methanol electro-oxidation reaction decreases. And the ratio $\mathrm{I}_{\mathrm{f}} / \mathrm{I}_{\mathrm{b}}$ increases to 2.73 after $100 \mathrm{CV}$ cycles, which demonstrating a better tolerance to carbonaceous poisoning. Having the best catalytic activity, NPG with Pt electrodeposited by $30 \mathrm{CV}$ cycles was selected for a longer check of stability, performing up to $300 \mathrm{CV}$ cycles and monitoring the decreasing of the current density. After 300 cycles the normalized current density reaches $0.66 \%$, 
demonstrating the good stability of Pt modified NPG electrode towards methanol electro-oxidation in alkaline solution (Fig. S4).
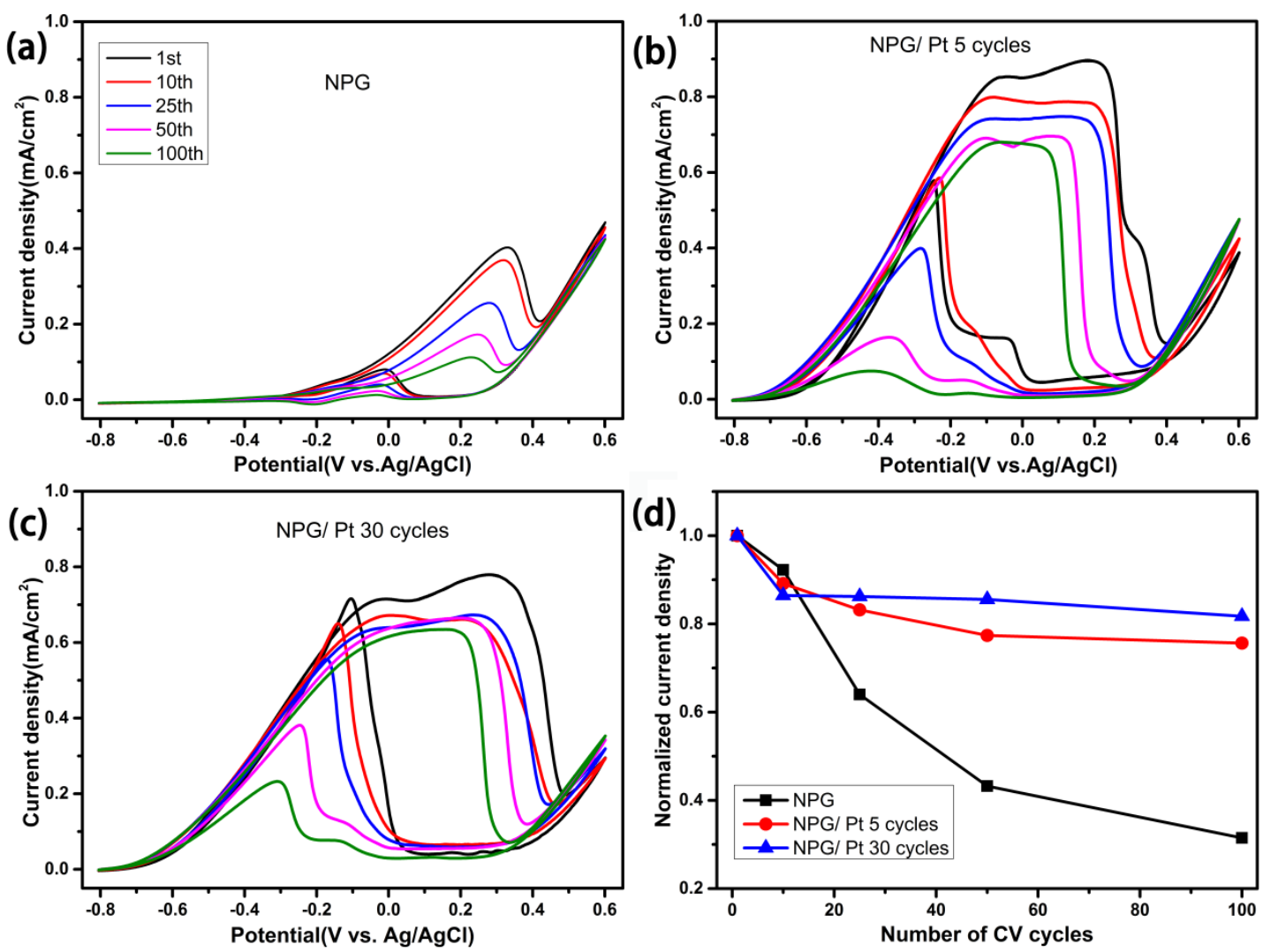

Figure 3. The electrocatalytic performance of as-prepared samples was tested for 100 cycles with a scan rate of $20 \mathrm{mV} / \mathrm{s}$ in $0.5 \mathrm{M} \mathrm{KOH}+5 \mathrm{M} \mathrm{CH}_{3} \mathrm{OH}$ solution (a) NPG, (b) NPG/Pt 5 cycles and (c) NPG/Pt 30 cycles. (d)The maximum current density in the selected CV scans is normalized with respect to the maximum value of the first scan and reported as a function of the number of cycles.

After electrochemical testing towards methanol electro-oxidation for 100 cycles, the as-prepared samples were investigated by SEM which was shown in Figure 4. The SEM images reveal the surface roughening of NPG (Fig.4a) and NPG with 5 cycles Pt electrodeposition (Fig.4b) during potential cycling, which is associated with the rapid diffusion of gold atoms at chemically active surface steps[41], therefore resulting in the loss of active surface area and the electrochemical activity of the electrode. For NPG with 30 cycles $\mathrm{Pt}$ electrodeposition, after 100 potential cycling, Pt nanoparticles coalesce into bigger nanoparticles, exposing the NPG substrate which loses the electro-catalytic activity (Fig.4c). The SEM images are consistent with our electrochemical characterization. Their results verified the synergistic catalytic function of Pt and NPG towards methanol electro-oxidation, and NPG with 30 cycles Pt electrodeposition exhibits higher activity and longer durability. 

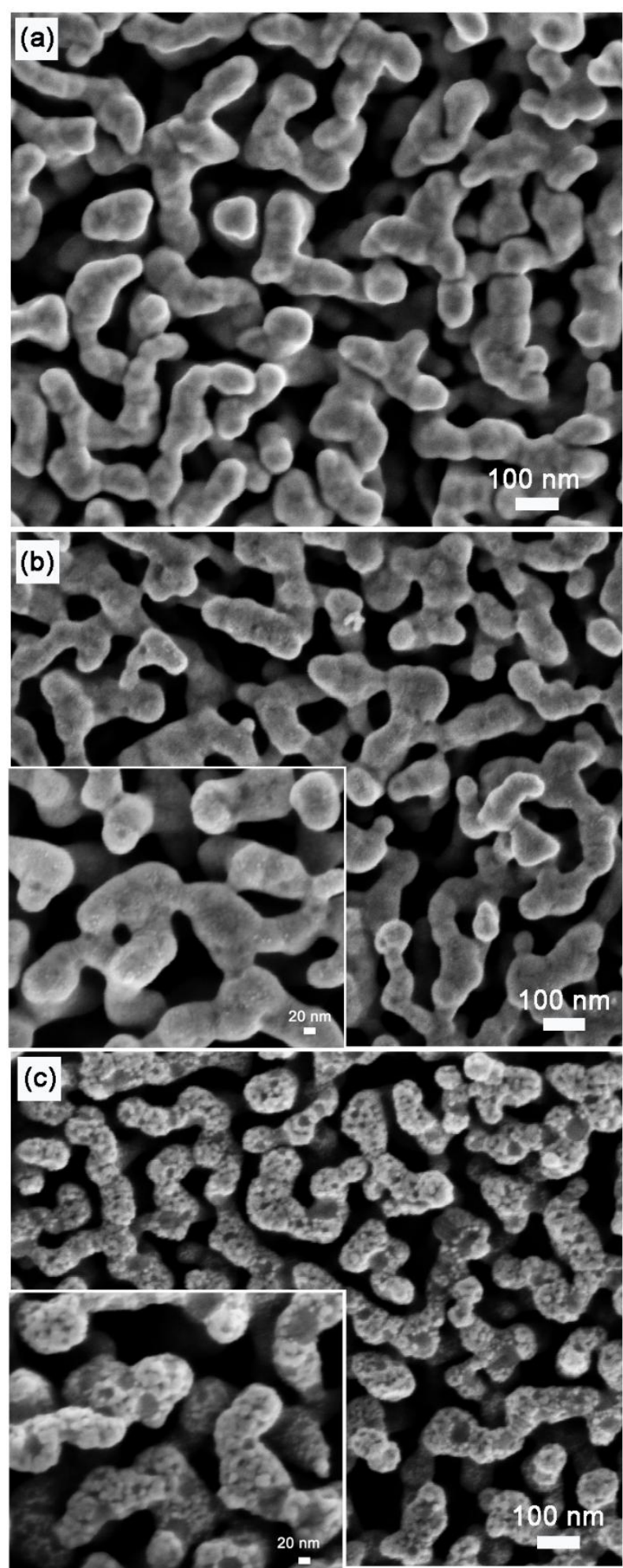

Figure 4. SEM images of the as-prepared samples after electrochemical testing in $0.5 \mathrm{M} \mathrm{KOH}+5 \mathrm{M}$ $\mathrm{CH}_{3} \mathrm{OH}$ solution for 100 cycles (a) NPG, (b) NPG/Pt 5 cycles and (c) NPG/Pt 30 cycles. Insets show the corresponding high magnification images. 


\section{Conclusion}

In this work, nanoporous gold prepared by de-alloying of an amorphous precursors was electrodeposited with Pt nanoparticles through cyclic voltammetry technique. Nanoporous gold, prepared in the form of ribbons, are free-standing and mechanically stable with a three dimensional bicontinuous structure of nanopores and ligaments of $60 \mathrm{~nm}$ average size; Pt nanoparticles are in the range of tens of $\mathrm{nm}$ and are wide spread on the ligament surface of nanoporous gold. The electro-catalytic properties of the as-prepared samples were tested through potential cycling towards methanol electro-oxidation in alkaline solution demonstrating activity for reaction even before $\mathrm{Pt}$ deposition. The bi-metallic nanostructured Pt-NPG can catalyze the methanol oxidation ranging from ranging from $-0.7 \mathrm{~V}$ to $0.4 \mathrm{~V}$ due to the synergistic intermetallic interaction for enhanced catalytic performance and durability. Stability of the electrodes was furthermore proved by performing multiple CV cycles and results indicate that NPG with 30 cycles Pt electrodeposition exhibits higher activity and longer durability maintaining the $66 \%$ of the normalized current density respect to the first cycle after 300 cycles. In conclusion, the synergistic effects between the nanoporous $\mathrm{Au}$ core, prepared by de-alloying an amorphous precursor, and Pt shell structure electro-deposited on ligaments contribute to the increase of electro-catalytic performance in terms of current density, stability and activity.

\section{Acknowledgements}

This work was supported by the funding scheme of the European Commission, Marie Curie Actions Initial Training Networks (ITN) in the frame of the project VitriMetTech Vitrified Metals Technologies and Applications in Devices and Chemistry, 607080 FP7-PEOPLE-2013-ITN and also by BINGO Project-Torino_call2014_L2_146 for Compagnia di San Paolo. Yanpeng Xue also thanks the support from Fundamental Research Funds for the Central Universities China (Project ID: FRF-TP-18-009A1).

\section{References}

[1] J. Erlebacher, M.J. Aziz, a Karma, N. Dimitrov, K. Sieradzki, Evolution of nanoporosity in dealloying., Nature. $410 \quad$ (2001) 450-453. doi:10.1038/35068529.

[2] I. Mccue, E. Benn, B. Gaskey, J. Erlebacher, Dealloying and Dealloyed Materials, Annu. Rev. Mater. Res. $46 \quad$ (2015) 1-24. doi:10.1146/annurev-matsci-070115-031739.

[3] X. Lu, E. Bischoff, R. Spolenak, T.J. Balk, Investigation of dealloying in Au-Ag thin films by quantitative electron probe microanalysis, Scr. Mater. 56 (2007) 557-560. doi:10.1016/j.scriptamat.2006.12.022.

[4] L. Battezzati, F. Scaglione, De-alloying of rapidly solidified amorphous and crystalline alloys, J. Alloys Compd. 509 (2011) S8-S12. doi:10.1016/j.jallcom.2010.12.209.

[5] F. Scaglione, A. Gebert, L. Battezzati, Dealloying of an Au-based amorphous alloy, Intermetallics. 18 (2010) 2338-2342. doi:10.1016/j.intermet.2010.08.005. 
[6] F. Scaglione, P. Rizzi, F. Celegato, L. Battezzati, Synthesis of nanoporous gold by free corrosion of an amorphous precursor, J. Alloys Compd. 615 (2014) S142-S147. doi:10.1016/j.jallcom.2014.01.239.

Gold Catalysts for Selective Methanol at Low Temperature, Science (80-. ). 327 (2010) 319-322. doi:10.1126/science.1183591.

[8] A. Wittstock, A. Wichmann, M. Bäumer, Nanoporous gold as a platform for a building block catalyst, ACS Catal. 2 (2012) 2199-2215. doi:10.1021/cs300231u.

[9] Q. Lu, G.S. Hutchings, W. Yu, Y. Zhou, R. V Forest, R. Tao, J. Rosen, B.T. Yonemoto, Z. Cao, H. Zheng, J.Q. Xiao, F. Jiao, J.G. Chen, Highly porous non-precious bimetallic electrocatalysts for efficient hydrogen evolution, Nat. Commun. 6 (2015) 6567. doi:10.1038/ncomms7567.

[10] L.Y. Chen, J.S. Yu, T. Fujita, M.W. Chen, Nanoporous copper with tunable nanoporosity for SERS applications, Adv. Funct. Mater. 19 (2009) 1221-1226. doi:10.1002/adfm.200801239.

[11] M. Zhang, A.M. Jorge Junior, S.J. Pang, T. Zhang, A.R. Yavari, Fabrication of nanoporous silver with open pores, Scr. Mater. 100 (2015) 21-23. doi:10.1016/j.scriptamat.2014.11.040.

[12] F. Scaglione, L. Battezzati, Metastable microstructures containing zero valent iron for fast degradation of azo dyes, J. Mater. Sci. 50 (2015) 5238-5243. doi:10.1007/s 10853-015-9071-4.

[13] F. Scaglione, F. Celegato, P. Rizzi, L. Battezzati, A comparison of de-alloying crystalline and amorphous multicomponent Au alloys, Intermetallics. 66 (2015) 82-87. doi:10.1016/j.intermet.2015.06.022.

[14] E.M. Paschalidou, F. Celegato, F. Scaglione, P. Rizzi, L. Battezzati, A. Gebert, S. Oswald, U. Wolff, L. Mihaylov, T. Spassov, The mechanism of generating nanoporous Au by de-alloying amorphous alloys, Acta Mater. 119 (2016) 177-183. doi:10.1016/j.actamat.2016.08.025.

[15] H. Liu, C. Song, L. Zhang, J. Zhang, H. Wang, D.P. Wilkinson, A review of anode catalysis in the direct methanol fuel cell, J. Power Sources. 155 (2006) 95-110. doi:10.1016/j.jpowsour.2006.01.030.

[16] V. Neburchilov, J. Martin, H. Wang, J. Zhang, A review of polymer electrolyte membranes for direct methanol fuel cells, J. Power Sources. 169 (2007) 221-238. doi:10.1016/j.jpowsour.2007.03.044.

[17] Y.J. Wang, N. Zhao, B. Fang, H. Li, X.T. Bi, H. Wang, Carbon-Supported Pt-Based Alloy Electrocatalysts for the Oxygen Reduction Reaction in Polymer Electrolyte Membrane Fuel Cells: Particle Size, Shape, and Composition Manipulation and Their Impact to Activity, Chem. Rev. 115 (2015) 3433-3467. doi:10.1021/cr500519c.

[18] N.S. Porter, H. Wu, Z. Quan, J. Fang, Shape-control and electrocatalytic activity-enhancement of pt-based bimetallic nanocrystals, Acc. Chem. Res. 46 (2013) 1867-1877. doi:10.1021/ar3002238.

[19] N. Kakati, J. Maiti, S.H. Lee, S.H. Jee, B. Viswanathan, Y.S. Yoon, Anode 
catalysts for direct methanol fuel cells in acidic media: Do we have any alternative for Pt or Pt-Ru?, Chem. Rev. 114 (2014) 12397-12429. doi:10.1021/cr400389f.

[20] S. Basri, S.K. Kamarudin, W.R.W. Daud, Z. Yaakub, Nanocatalyst for direct methanol fuel cell (DMFC), Int. J. Hydrogen Energy. 35 (2010) 7957-7970. doi:10.1016/j.ijhydene.2010.05.111.

[21] L. Huang, X. Zhang, Q. Wang, Y. Han, Y. Fang, S. Dong, Shape-Control of $\mathrm{Pt}-\mathrm{Ru}$ Nanocrystals: Tuning Surface Structure for Enhanced Electrocatalytic Methanol Oxidation, J. Am. Chem. Soc. 140 (2018) 1142-1147. doi:10.1021/jacs.7b12353.

[22] Y. Ding, M. Chen, Nanoporous Metals for Catalytic and Optical Applications, MRS Bull. 34 (2009) 569-576. doi:10.1557/mrs2009.156.

[23] T. Fujita, P. Guan, K. McKenna, X. Lang, A. Hirata, L. Zhang, T. Tokunaga, S. Arai, Y. Yamamoto, N. Tanaka, Y. Ishikawa, N. Asao, Y. Yamamoto, J. Erlebacher, M. Chen, Atomic origins of the high catalytic activity of nanoporous gold, Nat. Mater. 11 (2012) 775-780. doi:10.1038/nmat3391.

[24] B. Zugic, L. Wang, C. Heine, D.N. Zakharov, B.A.J. Lechner, E.A. Stach, J. Biener, M. Salmeron, R.J. Madix, C.M. Friend, Dynamic restructuring drives catalytic activity on nanoporous gold-silver alloy catalysts, Nat. Mater. 16 (2017) 558-564. doi:10.1038/nmat4824.

[25] X. Ge, R. Wang, P. Liu, Y. Ding, Platinum-Decorated Nanoporous Gold Leaf for Methanol Electrooxidation, Chem. Mater. 19 (2007) 5827-5829.

[26] J. Zhang, H. Ma, D. Zhang, P. Liu, F. Tian, Y. Ding, Electrocatalytic activity of bimetallic platinum-gold catalysts fabricated based on nanoporous gold, Phys. Chem. Chem. Phys. 10 (2008) 3250-3255. doi:10.1039/b718192b.

[27] S. Xiao, F. Xiao, Y. Hu, S. Yuan, S. Wang, L. Qian, Y. Liu, Hierarchical nanoporous gold-platinum with heterogeneous interfaces for methanol electrooxidation, Sci. Rep. 4 (2014) 4370. doi:10.1038/srep04370.

[28] Y. Xue, F. Scaglione, P. Rizzi, L. Battezzati, Improving the chemical de-alloying of amorphous $\mathrm{Au}$ alloys, Corros. Sci. 127 (2017) 141-146. doi:10.1016/j.corsci.2017.08.026.

[29] Y. Xue, F. Scaglione, E.M. Paschalidou, P. Rizzi, L. Battezzati, Excellent surface enhanced Raman scattering obtained with nanoporous gold fabricated by chemical de-alloying, Chem. Phys. Lett. 665 (2016) 6-9. doi:10.1016/j.cplett.2016.10.046.

[30] E.M. Paschalidou, F. Scaglione, A. Gebert, S. Oswald, P. Rizzi, L. Battezzati, Partially and fully de-alloyed glassy ribbons based on Au: Application in methanol electro-oxidation studies, J. Alloys Compd. 667 (2016) 302-309. doi:10.1016/j.jallcom.2016.01.181.

[31] F. Scaglione, Y. Xue, F. Celegato, P. Rizzi, L. Battezzati, Amorphous molybdenum sulphide @ nanoporous gold as catalyst for hydrogen evolution reaction in acidic environment, J. Mater. Sci. 53 (2018) 12388-12398. doi:10.1007/s 10853-018-2490-2.

[32] E. Budevski, G. Staikov, W.J. Lorenz, Electrocrystallization Nucleation and 
growth phenomena, 45 (2000) 2559-2574.

[33] I.S. Park, K.S. Lee, D.S. Jung, H.Y. Park, Y.E. Sung, Electrocatalytic activity of carbon-supported Pt-Au nanoparticles for methanol electro-oxidation, Electrochim. Acta. 52 (2007) 5599-5605. doi:10.1016/j.electacta.2006.12.068.

[34] Z. Borkowska, A. Tymosiak-Zielinska, G. Shul, Electrooxidation of methanol on polycrystalline and single crystal gold electrodes, Electrochim. Acta. 49 (2004) 1209-1220. doi:10.1016/j.electacta.2003.09.046.

[35] J. Zhang, P. Liu, H. Ma, Y. Ding, Nanostructured porous gold for methanol electro-oxidation, J. Phys. Chem. C. 111 (2007) 10382-10388. doi:10.1021/jp072333p.

[36] Z. Yang, S. Pedireddy, H.K. Lee, Y. Liu, W.W. Tjiu, I.Y. Phang, X.Y. Ling, Manipulating the $\mathrm{d}$ - Band Electronic Structure of Platinum- Functionalized Nanoporous Gold Bowls: Synergistic Intermetallic Interactions Enhance Catalysis, Chem. Mater. 28 (2016) 5080-5086. doi:10.1021/acs.chemmater.6b01925.

[37] Y. Du, J.J. Xu, H.Y. Chen, Ultrathin platinum film covered high-surface-area nanoporous gold for methanol electro-oxidation, Electrochem. Commun. 11 (2009) 1717-1720. doi:10.1016/j.elecom.2009.07.004.

[38] P. Rodriguez, M.T.M. Koper, Electrocatalysis on gold, Phys. Chem. Chem. Phys. 16 (2014) 13583-13594. doi:10.1039/c4cp00394b.

[39] J. Zhang, K. Sasaki, E. Sutter, R.R. Adzic, Stabilization of platinum oxygen reduction electrocatalysts using gold clusters, Science (80-. ). 315 (2007) 220-222. doi:10.1126/science.1134569.

[40] X. Chen, Y. Jiang, J. Sun, C. Jin, Z. Zhang, Highly active nanoporous Pt-based alloy as anode and cathode catalyst for direct methanol fuel cells, J. Power Sources. 267 (2014) 212-218. doi:10.1016/j.jpowsour.2014.05.089.

[41] T. Fujita, T. Tokunaga, L. Zhang, D. Li, L. Chen, S. Arai, Y. Yamamoto, A. Hirata, N. Tanaka, Y. Ding, M. Chen, Atomic observation of catalysis-induced nanopore coarsening of nanoporous gold, Nano Lett. 14 (2014) 1172-1177. doi:10.1021/n1403895s. 